\title{
Subjetivação e Psicologia Social: DUALIDADES EM QUESTÃO
}

\author{
Roberta Stubs Parpinelli ${ }^{\star}$ \\ Saulo Luders Fernandes $\star \star$
}

\begin{abstract}
Resumo
Iniciamos este ensaio com uma breve apresentação de duas heranças da psicologia social. A primeira refere-se ao dualismo sujeito-objeto que invadiu as ciências sociais proveniente do paradigma da ciência moderna. O segundo refere-se ao dualismo indivíduo-coletividade presente no nascimento da psicologia moderna. Ressaltamos as insuficiências desses dualismos para lidar com realidades sociais complexas, e com a finalidade de questioná-los, recorremos aos conceitos de subjetivação e rizoma desenvolvidos por Deleuze e Guattari. Para além do jogo dos dualismos sujeito-objeto e indivíduo-coletividade, apontamos para alternativas a partir de uma perspectiva mais plural e complexa da realidade.
\end{abstract}

Palavras-chave: sujeito-objeto; individuo-coletividade; subjetivação; rizoma.

\section{Subjectivation and Social Psychology: DUALISM IN QUESTION}

\begin{abstract}
This essay begins with a brief presentation of two social psychology inheritance. The first one refers to the subject-object dualism that encroached on social science descendent from the paradigm of modern science. The second one refers to the dualism individual-collectivity present in the rising of modern psychology. The mismatches of both dualism are bound to deal with complex social realities and in order to weaken them the concepts of subjectification and ryzoma from Deleuze and Guattari are brought up. Beyond the opposites subject-object and individual-collectivity, we indicate for alternatives from a much more plural and complex perspective of reality.
\end{abstract}

Keywords: subject-object; individual-collectivity; subjectification; ryzoma.

^Psicóloga. Mestrado em História da Educação pela Universidade Estadual de Maringá. Especialização em Saúde Mental pela Universidade Estadual de Maringá. Endereço: Universidade Estadual de Maringá, Centro de Ciências Humanas Letras e Artes. Av. Colombo, 5790 - Zona 07. Maringá, PR - Brasil. CEP: 87020-900.

E-mail:rostubs@yahoo.com.br

$\star \star$ Psicólogo. Mestre em Psicologia pela Universidade Estadual de Maringá. Docente da Universidade Federal de Alagoas.

E-mail: saupsi@yahoo.com.br 
As ciências sociais no percurso histórico da formação dos conhecimentos científicos estabelecem conflitos, tentativas de ruptura e sofrem enquadramentos dos pressupostos constitutivos da ciência moderna, sendo um deles o dualismo sujeito-objeto. A psicologia, bem como a psicologia social compreendidas como sistemas de saberes científicos, também se constituem dentro deste emaranhado histórico de conflitos e emolduramentos dos conhecimentos da modernidade. Em suas bases ontológicas e epistemológicas encontra-se subjacente a perspectiva moderna dualista que segmenta indivíduo e coletividade. Esses dualismos são, para dizer o mínimo, insuficientes para lidar com a complexidade da realidade social. Examina-se, aqui, uma alternativa que, de um lado, permita-nos abandonar tais dualismos, e que, de outro, ofereça-nos perspectivas mais adequadas para lidar com a complexidade da realidade social.

Com essa finalidade, realizamos, em primeiro lugar, uma reflexão acerca das marcas deixadas pelos pressupostos metodológicos e epistemológicos da modernidade no campo da psicologia social, apontando algumas raízes que ainda alimentam uma visão dualista dos fenômenos e da realidade social. Em segundo lugar, utilizamos as contribuições de Gilles Deleuze e Félix Guattari referentes ao conceito de subjetividade, delineando uma perspectiva de compreensão da realidade que possa transcender a separação entre sujeito e objeto, indivíduo e coletividade, possibilitando uma visão mais plural e complexa da realidade.

\section{DuAlismo SUJEITO-OBJETO NA CIÊNCIA MODERNA}

Pode-se dizer que a ciência moderna se instaurou sobre o pilar da emancipação, que, de certo modo, não se realizou. Haja vista o ideário modernista de liberdade e autonomia que empalideceu frente ao pilar de dominação social (SANTOS, 2000[1995]).

É fundamental entender como esse modelo de ciência interferiu na concepção de sujeito e de realidade e, conseqüentemente, no modo de se fazer ciência no campo das ciências sociais. De acordo com Santos (1999[1987]), o modelo de ciência que se instaurou após a revolução científica moderna tinha como bases a racionalidade científica e o modelo das ciências naturais. Para esse modelo, cunhado no pressuposto "conhecer significa quantificar" e aferir rigor cientifico por meio das medições, as formas de conhecimentos não mensuráveis, eram classificadas como conhecimentos irracionais e não científicos: recebe essa classificação tanto o senso comum quanto os chamados estudos humanísticos, posteriormente, denominados de ciências humanas.

Este modelo de ciência institui paulatinamente seus métodos como forma hegemônica de processamento e constituição dos conhecimentos. Por meio dos ditames metodológicos da neutralidade, da mensuração e da observação dos fenômenos naturais se levantaram os pilares que sustentam os saberes científicos. As ciências que procuravam outras vias metodológicas para produção de seus saberes (ciências humanas e sociais) ingressaram em um processo de marginalização e opressão, caracterizadas como desviantes pelo método hegemônico instituído. Percebe-se, nesse ínterim, que a discussão de modelos científicos e que a cisão 
existente entre as ciências naturais e as humanas vêm-se construindo desde a gênese da ciência moderna. Tal cisão influencia diretamente a concepção de conhecimento, bem como a relação do sujeito que conhece e o objeto de conhecimento.

O modelo das ciências naturais, representante dos pressupostos filosóficos e metodológicos da ciência moderna, busca por meio da mensuração e da observação categorizar os fenômenos com o intuito de conhecer suas leis para melhor controlá-los; fundamenta a construção do saber na descoberta do objeto. Objeto que, por sua vez, está à espera para ser desvelado. Nesta concepção, o objeto está estruturado a priori, cabendo ao cientista, apenas, descobrir e quantificar as leis que o regem para compreendê-lo. Nesta perspectiva, conhecer significa dividir para compreender, prever e controlar.

O objetivo maior de conhecer para dominar fundamenta-se na concepção de uma razão instrumental que, para se justificar, faz uso de classificações que acabam por reduzir a pluralidade e a complexidade que perpassa os fenômenos a serem desvelados. No campo das ciências humanas e sociais, o modelo científico moderno, na tentativa de descobrir os princípios que regem a natureza, segmenta o homem da realidade a qual pertence. O homem como ser cognoscente vai se debruçar sobre os objetos cognoscíveis para categorizar e definir as causas que determinam os fenômenos. Concepção dual que acaba por simplificar e estancar a processualidade complexa que vibra e faz vibrar a relação sujeito e objeto, sujeito-mundo.

A dissociação envolvendo o sujeito e o objeto, nos moldes da ciência moderna, é insuficiente para as ciências sociais, haja vista que o objeto das ciências humanas não é externo ao sujeito da pesquisa. Segundo Santos (1999[1987]), de acordo com o paradigma da ciência moderna, o objeto está segmentado e separado do sujeito cognoscente, sujeito e objeto acabam por estabelecer uma relação linear, na qual o sujeito, detentor da racionalidade, descobrirá as regras imutáveis do objeto cognoscível.

Segundo Santos (1999[1987]), a hegemonia metodológica da ciência natural não deixa espaço para outros métodos, acaba por desenhar um cerco hegemônico na tentativa de impor seu modelo metodológico também às ciências humanas e sociais. Diferente das ciências naturais que pressupõem um objeto a parte do sujeito, ainda que esta pressuposição possa ser contestada, já que todo conhecimento é fruto da constituição humana, é parte do sujeito que a produz, nas ciências humanas esta compreensão neutra e cindida da realidade se desfaz. Desfaz-se posto que, em termos relacionais, sujeito e objeto são a mesma coisa; se fazem na medida em que se relacionam. Seguindo esta concepção epistemológica e metodológica, não cabe conceber o processo de produção do saber de forma unilateral, do sujeito sobre o objeto. Na investigação das ciências humanas, é a relação que propicia a fundação do saber, não se trata mais de um objeto natural que pode ser medido e controlado por leis universais.

Nas ciências sociais e humanas o objeto de investigação é o próprio sujeito, nesta perspectiva o sujeito que concebe é ao mesmo tempo objeto concebido. Como afirma Santos (1999[1987]), nas ciências humanas todo conhecimento é autoconhecimento, a construção do saber é um ato criativo e não a descoberta 
de objetos alheios ao sujeito. A construção de saberes é constituição do próprio homem, seus valores, compreensões, crenças e desejos não se encontram em uma esfera a parte, posterior ou anterior à investigação, elas são integrantes do processo de produção do conhecimento. O homem se reconhece nos saberes que produz, os supostos objetos neutros postulados pelas ciências naturais, são, afinal, produtos da constituição humana.

Sujeito e objeto estão imersos na teia das relações sociais e em uma rede de relações culturais que não podem ser determinadas por leis universais. Essa característica das ciências humanas e sociais impossibilita a determinação de resultados e assertivas estáveis, pois se inserem no movimento próprio do desenvolvimento da sociedade, inteiramente vulnerável às descontinuidades das transformações sociais e culturais de determinado período histórico.

Vale ressaltar que a "natureza" subjetiva dos fenômenos sociais se desenha como importante elemento que dificulta e impossibilita a aplicação da metodologia das ciências naturais para o conhecimento social. A construção e a interpretação das ciências humanas e sociais ocorrem na relação com o objeto e não na pura observação e mensuração do mesmo. O objeto de estudo das ciências sociais é o ser humano e suas práticas em sociedade que, por sua vez, se configuram de maneira inconstante, num movimento ininterrupto no qual o sujeito se constitui e constrói o conhecimento à sua volta. Esta concepção de ciência deflagra uma série de tensões e contradições herdadas do projeto de ciência da modernidade e acaba por apontar a necessidade e urgência de outros modelos científicos, capazes de compreender a complexidade e a pluralidade que compõem as relações do homem com a sociedade. Sobre a necessidade, enfim, de outros modelos de pensamento.

É o que diz, também, Morin (1999[1982], p. 27, grifo do autor) ao afirmar que o pensamento moderno simplifica a complexidade dos fenômenos por meio da separação e redução, atribuindo: “a 'verdadeira' realidade não às totalidades, mas aos elementos; não às qualidades, mas às medidas; não aos seres e aos entes, mas aos enunciados formalizáveis e matematizáveis".

\section{Dualismo Indivíduo-Coletividade no Advento da Psicologia Social}

Posto que todo manual de psicologia nomeia Wilhelm Wundt como pai da psicologia, recorremos aos seus escritos para perceber de que maneira ele entendia a psicologia e o modo como esta mesma psicologia foi reduzida a manuais ao ser levada para os Estados Unidos.

A dualidade entre as ciências naturais e humanas também deixou registros epistemológicos no nascimento da psicologia. Na Alemanha, onde surgiu o laboratório de psicologia fundado por Wundt (1832-1920) em 1879, o conhecimento (Wissenschaft), era segmentado pelos pensadores e cientistas em dois campos: o conhecimento da natureza (Naturwissenschaft) e o conhecimento do espírito (Geisteswissenschaft). 
Wundt (2004[1897]) no processo de sistematização da psicologia científica constrói duas vertentes psicológicas com bases metodológicas diversas. Uma voltada para moldes próximos aos das ciências naturais, na verdade, uma vertente intermediária entre as ciências da natureza e do espírito, a qual, por meio do método da percepção interna (Innerrewahrnehmung) e da quantificação dos fenômenos psíquicos, compreenderia o funcionamento dos processos do psiquismo individual. O estudo desses processos seria o objeto da psicologia experimental, ciência intermediária entre as ciências da natureza e do espírito, e estava restrito ao exame dos funcionamentos da mente do indivíduo, à investigação dos processos básicos do espírito humano.

Para Wundt (2004[1897]), o psiquismo é entendido como processos. Dentre os processos psíquicos, como as emoções, os sentimentos e o pensamento, a volição é o que melhor caracteriza o psiquismo do indivíduo, pois é comum a todos eles, é a base ou o pano de fundo a partir do qual todos os processos psicológicos se configuram. A vontade é o norteador que dirige o psiquismo, como afirma Wundt (2004[1897], p.15):

Atos volitivos são reconhecidos universalmente como ocorrências compostas por uma série de modificações contínuas em qualidade e intensidade. Eles são típicos no sentido em que sua característica de ser ocorrência é verdadeira para todos os conteúdos da experiência psíquica.

O outro projeto de Wundt (2004[1897]) é a denominada "psicologia dos povos" (Volkerpsychologie), que apresenta objeto de estudo divergente ao da psicologia do indivíduo, como o pensamento, o mito, os costumes, a linguagem. Tais fenômenos têm a sua base formativa na coletividade e na cultura. Essa psicologia era amparada pelos métodos das ciências do espírito (Geisteswissenschaften), ou humanas. Tais métodos visam compreender, de forma qualitativa, a complexidade dos fenômenos culturais e sociais.

Para Wundt (2004[1897]), ambos os projetos eram independentes, a "psicologia dos povos ou social" não poderia ser reduzida ao método da psicologia do indivíduo, restrita aos processos básicos; se tal redução fosse feita, a dimensão histórica e coletiva presente na "psicologia social" seria perdida. Na intenção de não reduzir a pluralidade do objeto de pesquisa, Wundt acreditava que a ciência psicológica deveria ser abordada por vertentes metodológicas distintas.

A "psicologia dos povos" era a ciência que levava em conta as construções culturais e históricas, era uma reflexão a respeito da origem dos produtos culturais da experiência humana, não tinha uma base metodológica nas ciências naturais, e por esta razão, foi repudiada por alguns alunos de Wundt. Danziger (1979) afirma que, pautados no modelo positivista, estes alunos, especialmente Titchener e Külpe, procuravam estabelecer os limites da psicologia como "ciência natural", com o temor do retrocesso da psicologia ao pensamento metafísico, ao qual estava ligada anteriormente. 
Segundo Danziger (1979), esses alunos de Wundt distorceram a "psicologia dos povos", afirmando que ela era uma regressão à metafísica, visto que não baseava o seu conhecimento nas ciências naturais. Wundt (2004[1897]) também era um crítico da metafísica e lutava pela construção de uma psicologia científica. Ele repudiava os positivistas, que tinham o intuito de reduzir e ajustar todos os fenômenos aos métodos da ciência natural. Para ele, a ciência natural não abrangia todos os objetos das ciências, não era o único conhecimento válido, havia outras fontes epistemológicas sobre as quais o saber poderia ser construído, tanto é verdade que construiu uma segunda vertente psicológica baseada nas ciências do espírito.

No cerne da divisão realizada por Wundt entre a psicologia dos processos psicológicos individuais e a social, encontra-se presente a dualidade entre as esferas do sujeito e da coletividade. Na qual cada um destes campos de conhecimento tem um método e uma visão de ciência própria, uma mais centrada na consciência individual e outra nos fenômenos sociais e culturais. A psicologia do indivíduo, ao tentar compreender a consciência, isola os indivíduos do universo social, enquanto que a "psicologia dos povos", ao estudar a cultura, absorve o sujeito e obscurece as diferenças individuais. Com efeito, para Wundt (apud FARR, 2004[1996], p. 24, grifo nosso), a cultura "é algo que está na consciência dos indivíduos, mas é 'externa' a ela". Essa caracterização da cultura demonstra claramente a cisão entre os fenômenos individuais e coletivos: a cultura faz parte da consciência dos sujeitos ao mesmo tempo em que é externa à consciência.

Tal divisão entre o indivíduo e a coletividade ganha campo fértil nos Estados Unidos, tanto pela predominância do individualismo, quanto pela hegemonia das ciências naturais neste país. Este processo se fez conhecido como a americanização das ciências sociais, o qual, Farr (2004[1996]), baseado nos escritos de Allport, afirma que reduziu o objeto de investigação da psicologia social, que era o estudo das relações sociais na interface com os processos individuais, ao comportamento do indivíduo. Esse deslocamento conceitual repercutiu na psicologia social como um todo, que, da investigação dos fenômenos sociais, circunscreveuse ao estudo do comportamento individual.

Pode-se perceber nessa discussão a presença de dois modelos científicos dominantes (ciências naturais e ciências humanas) que vão se ramificar, como aponta Farr (2004[1996]), na formação de duas psicologias sociais: a psicologia "social psicológica" e a psicologia "social sociológica". A psicologia social psicológica fundamenta-se nas ciências naturais e procura determinar as leis que regem os fenômenos sociais com base nos estudos sobre o comportamento do indivíduo. A psicologia social sociológica fundamenta-se nas ciências sociais e procura determinar as leis que regem os fenômenos sociais com base na coletividade e nas relações sociais. Diferentemente da psicologia social psicológica, a psicologia social sociológica sobrepõe os fenômenos coletivos aos individuais. Nesta concepção, os elementos psicológicos e o indivíduo aparecem imersos no todo social, o que se sobressai é a coletividade e seus fenômenos culturais.

Tem-se, portanto, a presença de duas psicologias sociais que contribuem para a ampliação da dualidade envolvendo o individual e o coletivo. A psicologia social psicológica, ao eleger o comportamento individual como fonte de todos 
os fenômenos, reduz o social ao indivíduo, esquecendo as relações sociais constitutivas da coletividade. De modo inverso, a psicologia social sociológica, ao conceber os fenômenos sociais pelo viés da coletividade, dilui os acontecimentos singulares, bem como reduz o indivíduo às relações sociais.

Estas duas concepções de psicologia social acabam por reiterar um distanciamento entre o sujeito e coletividade, construindo modelos que não favorecem uma visão mais plural e complexa dos fenômenos individuais e coletivos. Ou o sujeito é fruto de determinantes sociais ou é produção de processos psicológicos internos. De uma forma ou de outra não há diálogo entre o sujeito e a coletividade, ambos estão circunscritos a esferas que tendem a afastar o particular do geral, o sujeito da coletividade, à qual, num movimento concomitante, se insere e constitui.

\section{SUbJETIVAÇ̃̃o: PARA ALÉM doS DUALISMOS}

Neste momento passamos a discutir a concepção de subjetividade da filosofia da diferença de Gilles Deleuze e Félix Guattari na tentativa de compreender o modo como, num movimento de co-engendramento recíproco, constituímos a nós mesmos e o mundo. A noção de subjetividade concebida por estes autores é marcada pela multiplicidade que se entremeia aos desejos e afetos, atravessando os processos subjetivos, intermitentemente perpassados por signos e símbolos, valores e normas de um dado momento da sociedade.

Essa multiplicidade que compõe o meio social e os sujeitos aí presentes constitui aquilo que Deleuze e Guattari denominam "processo de subjetivação". O conceito de processo de subjetivação foi inaugurado por Michel Foucault, principalmente na terceira fase de sua produção intelectual, que inclui os volumes 2 e 3 da História da sexualidade (FOUCAULT, 1985[1984], 2010), assim como seus cursos publicados postumamente, nos quais o autor toma como objeto de estudo os modos de subjetivação e as práticas de si, entendidos como maneiras de constituição dos sujeitos. A este terceiro momento da produção de Foucault dá-se o nome de "Estética da existência".

Os modos de subjetivação referem-se às práticas pelas quais os sujeitos se formam, configurando-se como um "ponto de interseção" entre os campos da arqueologia do saber e da genealogia do poder, discutidos pelo autor nos textos que antecedem os dois últimos volumes da História da sexualidade (FOUCAULT, 1985[1984], 2010). Relacionando a subjetividade com as relações de saber e de poder que marcam tal ou qual época, o autor aproxima a subjetividade da história, sendo esta reguladora de diferentes modos de subjetivação. Segundo Foucault (1985[1984]), a constituição dos sujeitos e da subjetividade envolve processos singulares e históricos de se fazer à experiência de si.

A constituição da subjetividade entendida em relação com as forças de saber e poder que perpassam determinado momento histórico abre caminho para compreender os modos de subjetivação dos sujeitos em sua relação com diferentes vetores que compõe a realidade; vetores sexuais, midiáticos, estéticos, etc. 
No entanto, por se tratar de práticas de si, modos peculiares de experienciar a subjetividade, as formas de subjetivação não estão, necessariamente, subsumidas aos dispositivos de saber e poder. Essas forças que perpassam intermitentemente a subjetividade influenciam os modos de subjetivação sem determiná-los, possibilitando aos sujeitos, enquanto prática de si, liberdade e autonomia para engendrarem modos de subjetivação não submetidos aos ditames do saber e do poder, permitindo um exercício de liberdade, de fuga de rótulos, estigmas, vícios e rotinas pessoais ditadas por saberes e poderes regulados socialmente. Deleuze (1998[1986]) afirma que há no pensamento de Foucault quatro pregas de subjetivação: a primeira diz respeito à parte material do sujeito, o corpo; a segunda dobra se refere à relação de forças que perpassa o sujeito social; a terceira dobra é a do saber ou da verdade; a quarta e última é a do 'fora', ou seja, a do "mundo exterior".

Não se trata mais de utilizar a noção de indivíduo como referencial único para entender a subjetividade, ocorre o imbricamento de uma perspectiva individual e contornada por uma totalidade exclusivamente intrapsíquica com a pluralidade que percorre o campo social. Nesta concepção, subjetividade e realidade objetiva imiscuem-se, a subjetividade está derramada sobre a realidade e o mundo que antes era "interno" verte sobre a realidade.

Sob a influência de Foucault (1985[1984]), a subjetividade é concebida por Deleuze e Guattari (1996[1980]) como um sistema aberto e "pulsátil" que se constitui em um movimento contínuo na medida em que se conecta com a multiplicidade de fatores que compõem a realidade. Essa multiplicidade é denominada por Guattari (1993[1987]) "equipamentos coletivos de subjetivação ou componentes de subjetivação". Segundo Guattari (2000[1992]), este termo designa os diferentes fatores sociais, animais, tecnológicos, históricos, psíquicos, mnemônicos, etc. que atuam no processo de subjetivação.

Pensar em termos de subjetivação acaba por romper com a dualidade envolvendo sujeito e objeto tão presente na ciência moderna. Ao invés de pensar um sujeito fechado em sua interioridade, a partir da qual a subjetividade se forma, melhor seria compreender a subjetividade como a intersecção de inúmeros componentes de subjetivação que se ligam e re-ligam intermitentemente, confluindo e endossando o processo de subjetivação dos sujeitos. Trata-se, pois, nos termos de Foucault (1982), de uma ontologia histórica de nós mesmos na qual a subjetividade, em seu processo de constituição, se mescla com uma série de influências próprias de cada momento histórico.

Esta perspectiva de análise compreende a subjetividade como um "objeto construído pelo conhecimento e também como campo de experiências do sujeito, não implica naturalmente nem necessariamente interioridade, substância ou permanência" (PRADO; MARTINS, 2007, p. 16). Rompe com uma série de tradições psicológicas que desenvolvem a questão da subjetividade de maneira essencialista, limitada sob o entorno da interioridade psíquica. Neste sentido, a dimensão do sujeito perde a centralidade, o subjetivo que antes era do domínio apenas do sujeito, passa a ser compreendido em relação aos vetores sociais com os quais se relaciona e os quais engendra. Pode-se afirmar que a subjetividade 
é também uma figura histórica, "tem menos a ver com uma suposta natureza humana do que com o instável jogo de forças dos enunciados e dispositivos". (PRADO; MARTINS, 2007, p. 16).

Nesta perspectiva, falar de subjetividade não é falar sobre uma essência ou uma realidade já dada, muito menos de alguma estrutura sempre idêntica a si. Entende-se subjetividade como um processo no qual o sujeito se apresenta como resultado da convergência de vetores de produção que ganha forma ao se conectar a múltiplos elementos como as relações familiares, a mídia, a cultura, a arte, a violência social, entre outros. Pensar a subjetividade enquanto produzida por instâncias individuais, coletivas e institucionais é concebê-la como um sistema vivo e se abrir para entender o outro como um ser mutável, que não se encontra, necessariamente, preso a uma identidade fixa (GUATTARI, 2000[1992]).

A própria noção de identidade se perde dentro deste entendimento de subjetividade, rompe-se com uma concepção de identidade enquanto instância internalizada e cristalizada em contornos imutáveis, reduzida a uma individualidade deslocada do espaço-tempo histórico. Qualquer tentativa de rotulação pode ser desfeita pela pulsação da subjetividade, ou seja, o movimento subjetivo possibilita ao sujeito se desprender de rótulos e estigmas passando a constituir outros planos existenciais. Formando linhas de fuga que escapam ou se valem de modo revolucionário das forças institucionais que homogeinizam as singularidades, abrindo portas para novas formas de subjetivação.

A capacidade da subjetividade se constituir e reconstituir continuamente se faz num movimento de íntima interligação entre fatores "extra" e "intrapsíquicos". Rolnik (1997, p. 14) elucida a forma como os elementos "externos" se conectam com a subjetividade, cuja superfície a autora denomina pele, e incitam movimentos de transformação.

\section{[...] outros fluxos vão entrando na composição da pele, formando outras constelações; aos poucos outros diagramas de relação de força emergem e assim sucessivamente. A cada vez que um diagrama se forma, a pele se curva novamente - nesta dinâmica, onde havia uma dobra, ela se desfaz; a pele volta a estender-se, curvando-se em outro lugar e de outro jeito; um perfil se dilui, enquanto outro se esboça. O que fica claro é que cada modo de existência é uma dobra da pele que delineia o perfil de uma determinada figura da subjetividade.}

Nesse ínterim, a subjetividade pode ser compreendida como um vir a ser, no qual o sujeito, ao se encontrar com diferentes equipamentos de subjetivação, entra em um movimento de entrelaçamento "interno" e "externo" e se dobra para uma composição subjetiva que, por sua vez, ganha forma e se faz funcionar. Esse entendimento mais plural da subjetividade verte sobre diferentes âmbitos da própria realidade, nos quais se inserem o psiquismo humano, os fenômenos psicológicos, a dimensão social e econômica da sociedade, a atuação da mídia, as expressões culturais, etc. Em suma, "subjetividade e realidade são inseparáveis". 
O conceito de rizoma formulado por Deleuze e Guattari (1996[1980]) pode contribuir para que se compreenda melhor a pluralidade que envolve a relação imanente entre subjetividade e realidade. Na concepção dos autores, as diferentes conexões realizadas no movimento de constituição da subjetividade ocorrem de maneira rizomática. $\mathrm{O}$ rizoma procede por alianças e conexões, não há pontos de chegada ou partida, ocorrem apenas campos de possíveis que se ligam ao múltiplo e ao heterogêneo. Deleuze e Guattari (2002[1980], 1996[1980]) enumeraram quatro princípios que caracterizam o rizoma: os princípios de conexão e heterogeneidade, multiplicidade, ruptura a-significante, cartografia.

A idéia de conexão e heterogeneidade confere ao rizoma a possibilidade de efetuar contínuas conexões. Traz-se à cena a idéia de movimento, de processualidade, na qual as diferentes partes do rizoma se conectam continuamente, possibilitando o encontro e a criação de novos elementos e novas configurações, $\mathrm{o}$ aparecimento do heterogêneo. No que se refere à multiplicidade, Deleuze e Guattari (2002[1980]) afirmam que a conexão de dois ou mais elementos implica não apenas uma complementaridade, mas uma mudança de natureza, eles se interpenetram e se transformam, surge uma nova forma e intensidade, pronta a se modificar novamente. Nesse ínterim, a multiplicidade, ao inserir a dimensão da criação contínua, derruba a noção de unidade, por exemplo, a unidade do Eu, pois, na medida em que o rizoma se transforma, ele dá vazão a novas formas, à diferença e à pluralidade.

Para se compreender a ruptura a-significante faz-se necessário entender o jogo de palavras e significados sobre o qual este conceito foi constituído. O sentido da palavra "a-significante" pode ser compreendido em oposição à palavra "significante". Compreende-se o a-significante em oposição ao signo, que possui um valor e sentido socialmente instituído, que caracteriza o significante. $\mathrm{O}$ a-significante representa o novo, diz respeito a um espaço conceitualmente descampado, carrega o potencial de transformar e atribuir outras roupagens a velhos e desgastados conceitos. Essa força de re-significação alimenta a conectividade do rizoma, abre arestas para novos encontros, dá abertura à multiplicidade do que ainda não foi estabelecido, possibilitando o surgimento do novo.

Quanto à cartografia, Deleuze e Guattari (1996[1980]) afirmam que a maneira mais apropriada de se entender as conexões do rizoma é através de mapas. "O mapa é aberto, é conectável em todas as suas dimensões, desmontável, reversível, suscetível de receber modificações constantemente" (DELEUZE; GUATTARI, 1996[1980], p. 22). O mapa, assim como o rizoma, possui múltiplas entradas e saídas, ele facilita cartografar os movimentos do rizoma, captando os territórios explorados e os deslocamentos engendrados.

A idéia de rizoma é fundamental para o pensamento de Deleuze e Guattari (1996[1980]), pois possibilita compreender e experimentar a pluralidade de elementos que se conectam num movimento que compõe tanto os sujeitos quanto a própria realidade. Voltar essa concepção ao processo de subjetivação possibilita compreender que a subjetividade se autoconstitui e auto-reconstitui por fluxos 
de "agenciamentos" com os quais ela está constantemente se conectando e reconectando. Essa concepção atribui à subjetividade uma mutabilidade que abre espaço à criação, ao novo e a novos desdobramentos. A filosofia da diferença de Deleuze e Guattari possibilita uma ampliação no entendimento de subjetividade, efetuando uma série de descentramentos na relação sujeito-objeto, subjetividadeobjetividade. De acordo com o pensamento desses autores, estas dimensões se encontram tão próximas umas das outras que elas quase não se diferenciam. $\mathrm{O}$ movimento entre um pólo e outro se faz de modo contínuo e resulta em constantes modificações que transmudam ambas as partes fazendo nascer outra instância. É este processo que possibilita dizer que não há uma separação entre sujeito e objeto, entre subjetivo e objetivo, eles se transformam mutuamente.

\section{Conclusão}

O conceito de subjetivação não prioriza raciocínios dualistas, posto que pretende contemplar o espaço da multiplicidade e da complexidade, o vasto campo do devir e dos agenciamentos. Expande-se para além de concepções que se prendem na distinção entre corpo e mente, sujeito e objeto, indivíduo e coletividade, excesso da face utilitária do pensamento moderno. Visa compreender o movimento constante de constituição dos sujeitos em relação com os meios nos quais vivem. Essa perspectiva não se foca em um entendimento epistemológico que se limite ao plano do sujeito que constrói e apreende o conhecimento. Não se trata de uma epistemologia voltada para o ser cognoscente, calcada no primado da racionalidade, mas sim de uma epistemologia que revele as relações do sujeito com os mundos, do sujeito com as realidades e também com os objetos sobre os quais se debruça na construção de conhecimentos.

Voltar as vistas para a processualidade que compõe a realidade, pede por uma perspectiva que contemple o modo como vivemos em sociedade. Trata-se, pois, de deslocar o olhar para uma ontologia do presente, ou ainda, para uma ontologia crítica de nós mesmos, cujo enfoque maior se volta para o modo como as forças de saber e poder articulam o que somos, pensamos, fazemos e vivemos em nosso presente histórico (FOUCAULT, 2000). O que emerge é todo um campo de possíveis que se desenha e ganha forma à medida que nos relacionamos com os mundos. Movimento que evidencia a pulsação da subjetividade em toda arquitetura do real e que confere visibilidade aos contornos que o co-engendramento recíproco e indissociável de nós mesmos com o mundo assume e pode assumir na atual tessitura da vida.

No que tange a Psicologia Social, este salto epistemológico, que apontamos como necessário, ganha expressividade nas chamadas pesquisas participativas que visam ultrapassar a distância entre sujeito e objeto estabelecendo relações mais horizontais na construção do conhecimento, o que possibilita a configuração de saberes políticos que não se destituem dos interstícios das realidades sociais como suas bases formativas. Com referencias na Análise Institucional ${ }^{1}$, e na Filosofia da diferença podemos citar a Pesquisa-Intervenção que parte da idéia de que "todo conhecer é um fazer", não uma reiteração de verdades. A teoria entra aqui 
como conceito-ferramenta, na qual as técnicas e metodologia aparecem como fonte de informação, não como produção de dados. A idéia é se insinuar em e por diferentes modos de subjetivação para disparar ou dar visibilidade a linhas de diferenciação. É no encontro que se demarca e se cria linhas duras e vetores de ultrapassagem.

\section{Nota}

${ }^{1}$ Alguns são os expoentes da Análise Institucional: Lourau (1993; 1997), Lapassade (1998), Guattari (1985; 2000[1992]), Baremblitt (1992).

\section{REFERÊNCIAS}

BAREMBLITT, G. Compêndio de Análise Institucional e outras correntes. Rio de Janeiro: Rosa dos Tempos, 1992.

DANZIGER, K. The positivist repudiation of Wundt. Journal of the History of the Behavioral Sciences, Malden, v. 15, n. 3, p. 205-230, Jul. 1979.

DELEUZE, G.; GUATTARI, F. Mil Platôs (1980). São Paulo: 34, 1996. v. 1.

DELEUZE, G. Foucault (1986). Tradução M. T. C. Albuquerque. São Paulo: Brasiliense, 1998.

Deleuze, G.; Guattari, F. Mil platôs (1980). Tradução Suely Rolnik. São Paulo: 34, 2002. v. 4.

FARR, R. As raizes da psicologia social moderna (1996) Tradução Pedrinho Arcides Guareschi e Paulo Maya. Petrópolis: Vozes, 2004.

FOUCAULT, M. The subject and power. Critical Inquiry, Chicago, v. 8, n. 4, p. 777-795, summer. 1982.

FOUCAULT, M.. História da sexualidade 2: o uso dos prazeres (1984). Tradução C. S. Martins. Rio de Janeiro: Graal, 1985.

FOUCAULT, M.. História da sexualidade 3: o cuidado de si. Rio de Janeiro: Graal, 2010.

FOUCAULT, M. O que são as luzes? In: Foucault, M. Arqueologia das ciências e história dos sistemas de pensamentos. Rio de Janeiro: Forense Universitária, 2000. p. 333-351.

GUATTARI, F. Da produção de subjetividade (1987). Tradução Suely. Rolnik.

In: PARENTE, A (Org.). Imagem Máquina. São Paulo: 34, 1993. p. 177-191. 
GUATTARI, F. Caosmose: um novo paradigma estético (1992). Tradução A. L. de Oliveira e L. C. Leão. São Paulo: 34, 2000.

GUATTARI, F.; ROLNIK, S. Micropolítica: cartografias do desejo. São Paulo: Ática, 1985.

LAPASSADE, G. Microssociologie de la vie scolaire. 1. ed. Paris: Econômica, 1998.

LOURAU, R. Análise Institucional e práticas de pesquisa. 1. ed. Rio de Janeiro: UERJ, 1993.

LOURAU, R. Une introduction à l'analyse institutionnelle. 1. ed. Paris: Econômica, 1997.

MORIN, E. Ciência com consciência (1982). Rio de Janeiro: Bertrand Brasil, 1999.

PRADO FILHO, K. E MARTINS, S. A subjetividade como objeto da(s) psicologia(s). Psicologia e Sociedade, Porto Alegre, v. 19, n. 3, p. 14-19. set./ dez. 2007.

ROLNIK, S. Psicologia: subjetividade, ética e cultura. In: EIRADO, A. S., NEVES, C.A.B.; RAUTER, C., PASSOS, E.(Org.). Saúde loucura: subjetividade: questões contemporâneas. São Paulo: Hucitec, 1997. p.13-21.

SANTOS, B. S. Um discurso sobre as ciências (1987). Porto: Afrontamento, 1999.

SANTOS, B. S. Pela mão de Alice: o social e o político na pós-modernidade (1995). São Paulo: Cortez, 2000.

WUNDT, W. Outlines of psychology (1897). Toronto: York University, 2004. Disponível em: <http://www.yorku.ca/dept/psich/classics/outlines/sec2.htm>. Acesso em: 4 mar. 2004.

Recebido em: setembro de 2009

Aceito em: janeiro de 2011 